\title{
Prevalence and treatment of panic disorder in bipolar disorder: systematic review and meta-analysis
}

\author{
Antonio Preti, ${ }^{1,2}$ Jelena Vrublevska, ${ }^{3}$ Areti Angeliki Veroniki, ${ }^{4}$ Tania B Huedo-Medina, ${ }^{5}$ \\ Odysseas Kyriazis, ${ }^{6}$ Konstantinos N Fountoulakis ${ }^{6}$
}

\begin{abstract}
${ }^{1}$ Genneruxi Medical Center, Cagliari, Italy; ${ }^{2}$ Center for Consultation-Liaison Psychiatry and Psychosomatics, University Hospital of Cagliari, Cagliari, Italy; ${ }^{3}$ Department of Psychiatry and Narcology, Riga Stradins University, Riga, Latvia; ${ }^{4}$ Li Ka Shing Knowledge Institute, St Michael's Hospital, Toronto, Ontario, Canada; ${ }^{5}$ Department of Allied Health Sciences, University of Connecticut, Storrs, Connecticut, USA; ${ }^{6} 3 r d$ Department of Psychiatry, School of Medicine, Aristotle University of Thessaloniki, Thessaloniki, Greece

Correspondence to Professor Konstantinos N Fountoulakis, 3rd Department of Psychiatry, School of Medicine, Aristotle University of

Thessaloniki, Thessaloniki 54124,Greece; kostasfountoulakis@gmail.com
\end{abstract}

\begin{abstract}
Question Recent data suggest that anxiety disorders are as often comorbid with bipolar disorder (BD) as with unipolar depression. The literature on panic disorder (PD) comorbid with BD has been systematically reviewed and subject to meta-analysis.

Study selection and analysis The Preferred Reporting Items for Systematic Reviews and Meta-Analyses guidelines were thoroughly followed for literature search, selection and reporting of available evidence. The variance-stabilising Freeman-Tukey double arcsine transformation was used in the meta-analysis of prevalence estimates. Both fixed-effect and random-effects models with inverse variance method were applied to estimate summary effects for all combined studies. Heterogeneity was assessed and measured with Cochran's 0 and $\mathrm{I}^{2}$ statistics.

Findings Overall, 15 studies ( $n=3391)$ on cross-sectional prevalence and 25 independent lifetime studies ( $n=8226)$ were used to calculate pooled estimates. The overall random-effects point prevalence of PD in patients with $\mathrm{BD}$, after exclusion of one potential outlier study, was $13.0 \%(95 \% \mathrm{Cl} 7.0 \%$ to $20.3 \%$ ), and the overall random-effects lifetime estimate, after exclusion of one potential outlier study, was $15.5 \%$ (95\% Cl $11.6 \%$ to $19.9 \%)$. There were no differences in rates between BD-I and BD-II. Significant heterogeneity $\left(I^{2}>95 \%\right)$ was found in both estimates.

Conclusions Estimates that can be drawn from published studies indicate that the prevalence of PD in patients with BD is higher than the prevalence in the general population. Comorbid PD is reportedly associated with increased risk of suicidal acts and a more severe course. There is no clear indication on how to treat comorbid PD in $\mathrm{BD}$. Findings from the current meta-analysis confirm the highly prevalent comorbidity of PD with $\mathrm{BD}$, implicating that in patients with $\mathrm{BD}, \mathrm{PD}$ might run a more chronic course.
\end{abstract}

\section{BACKGROUND}

Patients with bipolar disorder (BD) are exposed to psychiatric comorbidity, with longitudinal rates that can be higher than $50 \%$ and may reach even $70 \%$. Psychiatric comorbidity is one of the major reasons BD is often as severe as schizophrenia. ${ }^{1}$

Psychiatric comorbidity in BD goes often undetected and undertreated in the clinical setting. ${ }^{2}$ This may depend on clinicians' inclination to use a single, comprehensive primary diagnosis to deal with the patients, often neglecting the residuals symptomatology. Some symptoms-such as anxiety - may also hide within the multifaceted landscape of BD. Residual untreated symptoms are not unusual in BD with psychiatric comorbidity, and sometimes treatments aimed at the 'primary' condition might negatively impact on the course of the comorbid condition, worsening its course.

In patients with $\mathrm{BD}$, anxiety is extremely common, and it can be expressed both as an isolated symptom and as a full-blown syndrome. Kraepelin included anxiety in the core features of $\mathrm{BD}$, also considering it a typical feature of the different clinical subtypes of the major condition. However, it was not until the latest decades that the interest in the manifestations of anxiety in the course of $\mathrm{BD}$ peaked in the published literature.

In general, comorbid anxiety is related to worse outcome, may affect recovery, leading to longer time from index mood episode to full remission of symptoms, particularly in depression, may favour earlier relapse, and associates to lower quality of life. ${ }^{34}$ Its treatment is problematic. ${ }^{5-8}$

Age at onset in patients with comorbid panic disorder (PD) was reported to be younger than in those without comorbidity. ${ }^{9}$ More depressive episodes, and possibly higher risk of suicide and suicide attempt, also were reported. ${ }^{10} 11$ Indeed, a negative impact of comorbidity of PD with the course and outcome of BD has been described.
Studies reported a wide variability of the cross-sectional prevalence of $\mathrm{PD}$ in $\mathrm{BD}$, ranging from $2.3 \%$ to $62.5 \%$, while the longitudinal prevalence ranged from $2.9 \%$ to $56.5 \% .^{12-15}$

Overall, data on cross-sectional and longitudinal prevalence suggest that patients with $\mathrm{BD}$ share with patients with schizophrenia, or unipolar an equivalent rate of $\mathrm{PD}$, which, nevertheless, is several times higher than the rate expected for the general population. However, detailed analysis is lacking. Precise information on comorbidity of PD with BD may serve the purpose of targeting those conditions that are known to affect treatment response and recovery, and that may increase the risk of suicidality and the chance of developing a substance use disorder. Moreover, the treatment of comorbid PD may reveal challenging, both because of the increased risk of adverse effects and the greater chance of medication-induced mood switch.

\section{OBJECTIVE}

This study set out to systematically review the literature about BD comorbid with PD BD. Retrieved data were subject to meta-analysis to extract both cross-sectional (point) and longitudinal rates of comorbidity.

\section{STUDY SELECTION AND ANALYSIS}

The recommendations of the Preferred Reporting Items for Systematic Reviews and Meta-Analyses (PRISMA) statement were followed in performing the review.

Data on the comorbidity of PD with BD were extracted from published literature, which were retrieved from PubMed/MEDLINE, from inception until 1 August 2017, on the basis of a search code that was developed by two authors (KNF, JV).

The following terms were used to scan PubMed database: 'Bipolar' (all fields) OR 'manic' (all fields) OR 'mania' (all fields) OR 'manic depression' (all fields) OR 'manic depressive' (all fields) AND 'panic' (all fields). 
Online supplementary appendix A details the combination of search terms that were used in the PubMed/MEDLINE interrogation, as well as all other search details.

Only studies in the English language were included. The search was enriched by a thorough scan of the reference lists of relevant books and reviews. $^{13-17}$

A first reviewer (KNF) conducted a screen of titles and abstracts of the extracted list of references for inclusion, with a validation check by a second reviewer (JV). In case of uncertainty on inclusion, the full-text article was accessed. Discrepancies were solved through discussion, until the achievement of a consensus.

\section{Criteria for study selection}

- Studies that included primary data concerning the comorbidity of PD in adult (over 18 years old) patients with BD: essentially, the number of patients with confirmed diagnosis of $\mathrm{BD}$ and with a comorbid diagnosis of PD.

- Studies published in the English language.

\section{Data abstraction and quality assessment}

A previously pilot-tested standardised coding system was used by two authors (JV, KNF) for data extraction. The following information was derived from the articles: authors' name, publication year, location, sample size, criteria for diagnosis, procedure for diagnosis (either clinical decision or diagnosis based on standardised or semistandardised interview), number of cases with $B D$, number of cases with PD and number of cases with any other diagnostic group when used as comparison. For each study, one reviewer (KNF) abstracted the relevant data and a second reviewer (JV) verified the extraction for completeness and accuracy. Discrepancies in extraction/scoring were solved through discussion.

\section{FINDINGS}

Eventually, 16 studies with cross-sectional data and 26 with longitudinal data were included in the analysis. Overall, nine studies with data on BD-I were entered in the related sensitivity analysis, while four studies with data on BD-II were entered in the sensitivity analysis on BD-II.

The PRISMA flow chart is shown in the online supplementary appendix. The detailed results are also shown in the online supplementary appendix. The included studies with cross-sectional estimates are reported in table 1, while the details on included studies with lifetime estimates are reported in table 2 (see online supplementary appendix for the reference list of included studies).

\section{Cross-sectional (point) prevalence of comorbid PD}

The overall cross-sectional estimate of PD in patients diagnosed with $\mathrm{BD}$ was $11.5 \%$ (95\% Cl $10.4 \%$ to $12.6 \%$ ) in the fixed-effect model, and it was $15.1 \%(95 \% \mathrm{Cl} 7.9 \%$ to $24.0 \%)$ in the random-effects model (figure 1). Across studies there was a variation in the cross-sectional prevalence of $\mathrm{PD}$ in $\mathrm{BD}$, a likely reflection of the sociodemographics and clinical characteristics of the samples (figure 1). No relevant publication bias emerged from the funnel plot (online supplementary appendix figure A) and the Egger's or Begg and Mazumdar rank correlation test (online supplementary appendix figure B). Heterogeneity was substantial: $\left.\right|^{2}=95.9 \%(95 \% \mathrm{Cl}$ $94.5 \%$ to $97.0 \%$ ), estimated between-study variance $=0.15$ (figure 1 and table 3). However, the Baujat plot (online supplementary appendix figure C) suggested that the studies with the greatest contribution to the overall heterogeneity had a small to moderate influence on the result but one. The standardised residuals plot and the radial plot suggested just one sample was potential outlier (online supplementary appendix figure D).

Indeed, this sample, with patients with both BD-I and BD-II, had one of the highest cross-sectional estimated prevalence of PD.
After exclusion of this outlier, the overall fixed-effect cross-sectional estimate of $\mathrm{PD}$ in patients diagnosed with $\mathrm{BD}$ went to a small decrease, being now $10.6 \%(9.5 \%-11.7 \%)$, while the random-effects estimate was $13.0 \%(7.0 \%-20.3 \%)$ (table 3$)$.

Subgroup analyses, with inclusion/exclusion of studies according to the nature of the sample, did not reveal relevant changes in the estimates of the random-effects model, nor a substantial attenuation of heterogeneity (see table 3 for details).

No difference in cross-sectional prevalence rates was found between BD-I and BD-II.

The meta-regression of data without the outlier on age and gender ratio showed that neither age (coefficient $=0.011 ; z=-0.48 ; P=0.64$; $\mathrm{I}^{2}=94.6 \%$ ) nor gender ratio (coefficient $=-0.150 ; z=-0.94 ; P=0.36$; $\left.\mathrm{I}^{2}=94.6 \%\right)$ was related to the cross-sectional prevalence estimate of $\mathrm{PD}$ in $\mathrm{BD}$.

\section{Longitudinal prevalence of comorbid PD}

There were 26 studies detailing data on lifetime prevalence of PD in patients diagnosed with $\mathrm{BD}$ (figure 2), yielding 25 rates, some of them further grouped into BD-I and BD-II estimates (table 2). The longitudinal estimate of $\mathrm{PD}$ in patients diagnosed with $\mathrm{BD}$ was $15.5 \%(95 \% \mathrm{Cl} 14.7 \%$ to $16.3 \%$ ) in the fixed-effect model, and it was $16.8 \%$ (95\% Cl $12.2 \%$ to $22.0 \%$ ) in the random-effects model. Again, the composition of the sample by sociodemographic (male:female ratio, age range) and clinical (BD subtypes, phase of the disorder at assessment) variables conditioned a wide variability of the longitudinal prevalence of PD across studies (figure 3).

Some asymmetry, suggesting publication bias, emerged from the funnel plot (online supplementary appendix figure A), but the Egger's or Begg and Mazumdar rank correlation test did not reveal statistically significant bias (online supplementary appendix figure B). Heterogeneity was substantial: $\left.\right|^{2}=95.6 \%$ (95\% Cl $94.5 \%$ to $\left.96.5 \%\right)$. The Baujat plot suggested that two studies among those with the greatest contribution to the overall heterogeneity also had the greatest influence on the result (online supplementary appendix figure A). However, the radial plot and the standardised residuals plot suggested just one potential outlier, and a different one (online supplementary appendix figure $\mathrm{E})$.

After exclusion of one potential outlier study, the longitudinal estimate of $\mathrm{PD}$ in patients diagnosed with BD was $15.5 \%$ (95\% Cl $11.6 \%$ to $19.9 \%$ ) in the random-effects model. No difference in longitudinal prevalence rates was found between $\mathrm{BD}-\mathrm{I}$ and $\mathrm{BD}-\mathrm{II}$ (table 3).

Heterogeneity remained substantial in analyses by subgroup, suggesting the sample diagnosis or phase of the disorder was not the main reason explaining it (table 3 ). Meta-regression showed no relationship of estimates with age (coefficient $=0.005 ; z=0.44 ; P=0.66$; $\mathrm{I}^{2}=95.9 \%$ ), gender ratio (coefficient $=-0.029 ; \quad z=-0.38 ; P=0.70$; $\mathrm{I}^{2}=92.8 \%$ ) or the diagnostic procedure (Structured Clinical Interview for Diagnostic Statistic Manual (DSM) vs any other: coefficient $=0.039$; $\left.z=0.34 ; P=0.73 ; I^{2}=95.5 \%\right)$.

\section{Comparison of BD with other diagnoses}

Table 3 summarises the details on the prevalence rates of PD in patients with BD. Cross-sectional pooled rates indicate that $13 \%$ of patients with $\mathrm{BD}$ suffer from PD. This estimate is roughly similar to that reported for patients with schizophrenia or unipolar depression, and it is several times higher than the rate expected for the general population. The pooled longitudinal rate for PD in patients with BD is $15.5 \%$, which is similar to that reported for patients with unipolar depression but several times higher in comparison with that reported in the control population.

PD probably presents with a chronic rather than episodic course in patients with $\mathrm{BD}$ and unipolar depression, as suggested by the negligible difference between cross-sectional and longitudinal prevalence. 


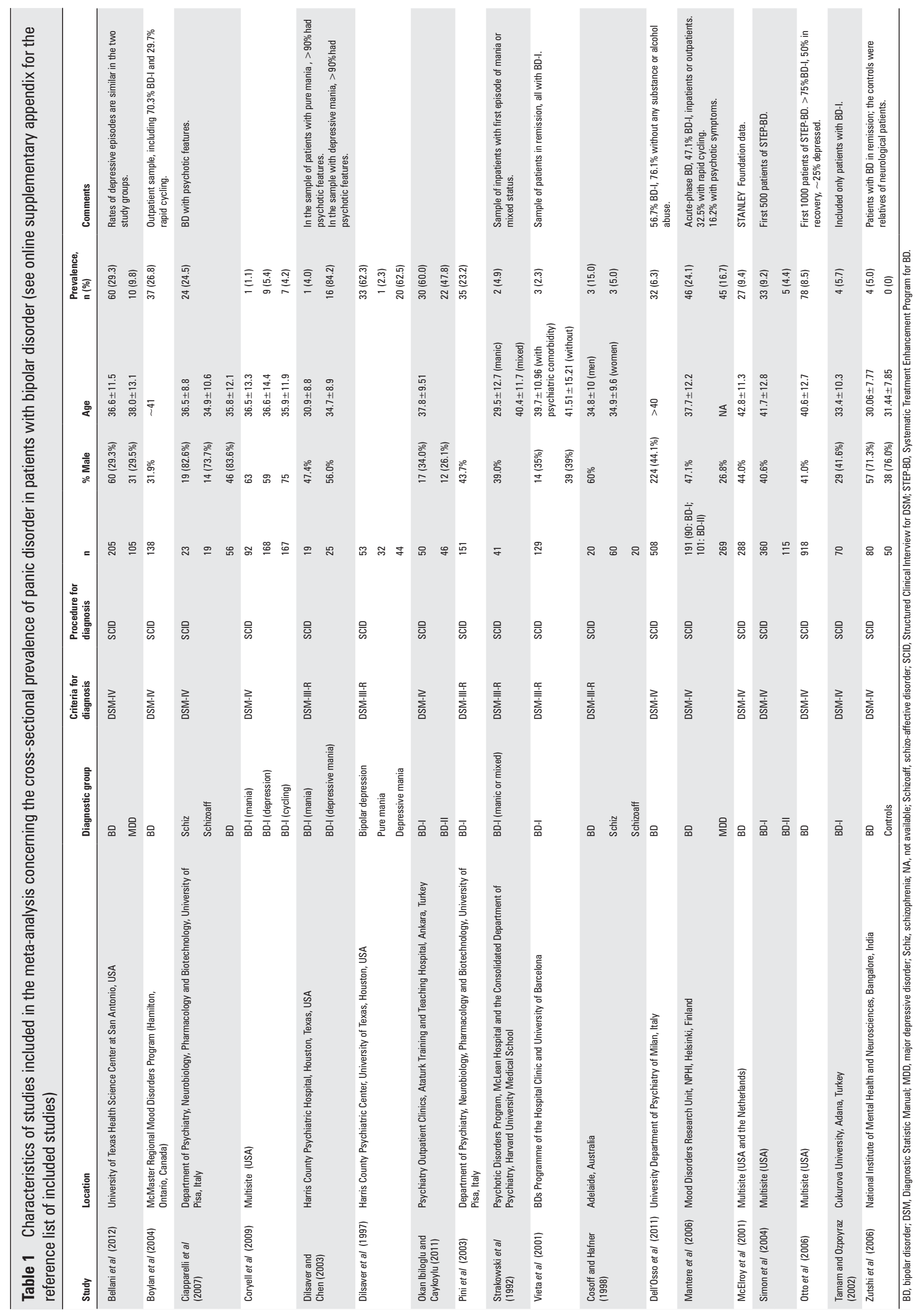




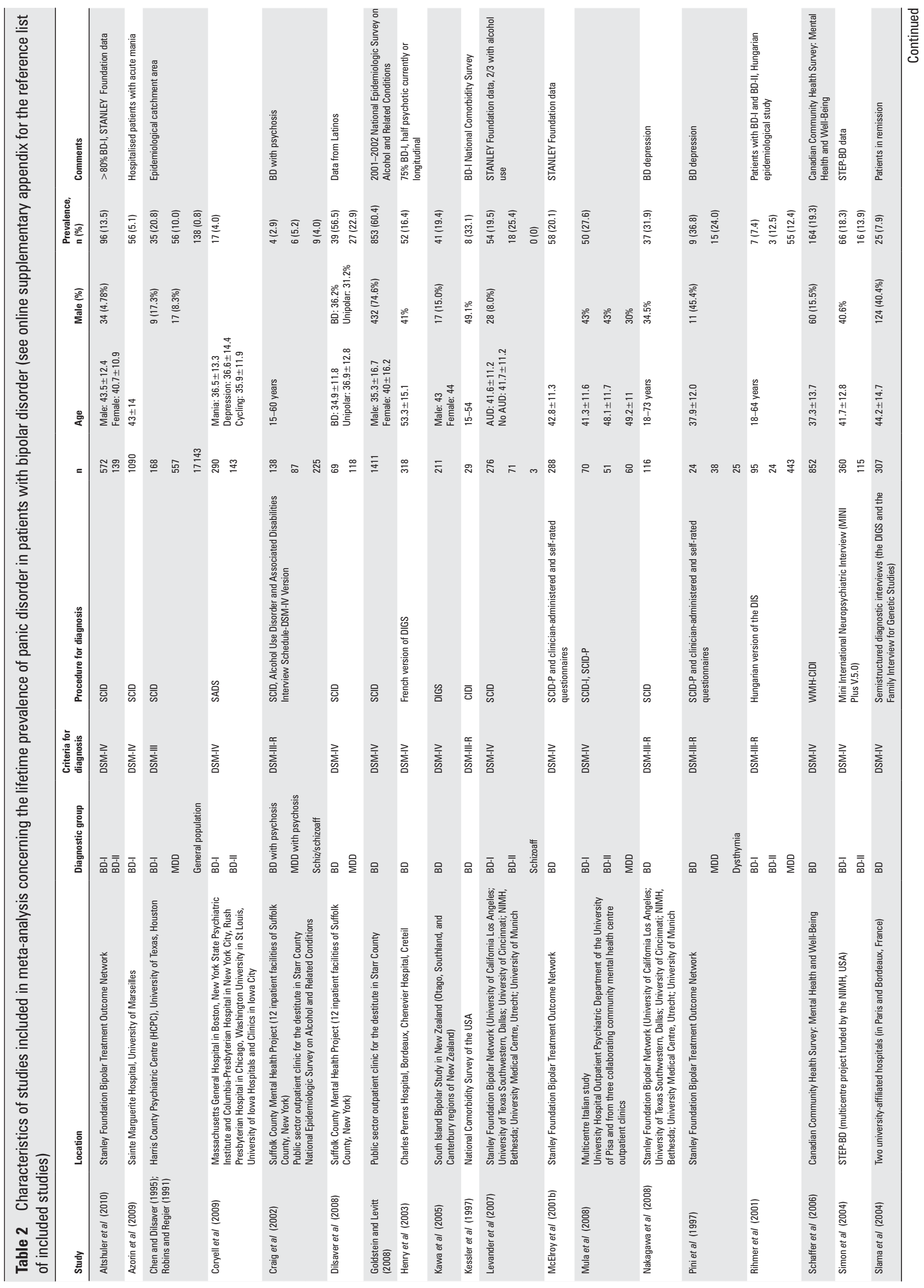




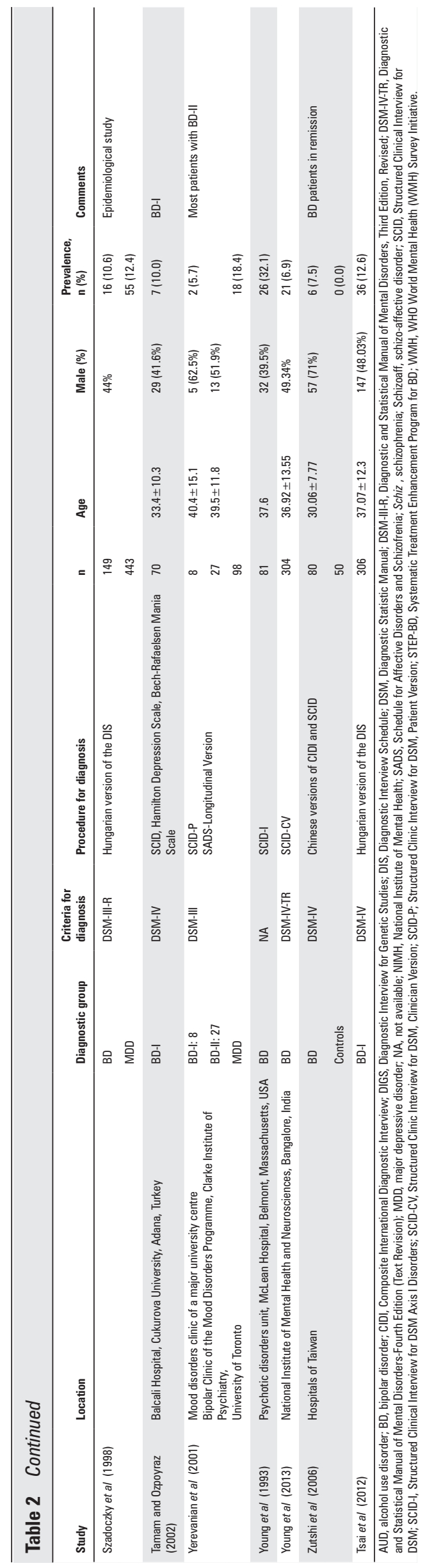

The prevalence of $\mathrm{PD}$ in people without comorbid disorder was reported in just one study, and it was $0 \%$ (out of 50 subjects), way much lower than the prevalence found in patients with $\mathrm{BD}$ in the same study $(5 \%)$ or the estimates found in the present meta-analysis.

Cross-sectional estimates of PD in patients with $\mathrm{BD}$ were confronted with those observed in patients with major depressive disorder (MDD) in two studies only. A higher cross-sectional prevalence of PD in patients with $\mathrm{BD}$ was found than in patients with MDD (online supplementary appendix figure $\mathrm{F}$ ): test for subgroup differences (based on random-effects model): $\mathrm{Q}=7.98, \mathrm{df}=1, \mathrm{P}=0.0047$. However, in these two studies the cross-sectional estimates of $\mathrm{PD}$ in patients with $\mathrm{BD}$ were higher than the pooled estimates in the overall meta-analysis on cross-sectional data. Moreover, heterogeneity was substantial: $1^{2}=86.4 \%(66.9 \%-94.4 \%)$; $\mathrm{Q}=22.0, \mathrm{df}=3, \mathrm{P}<0.0001$.

Six studies (published in seven papers) reported longitudinal estimates of $\mathrm{PD}$ in patients with $\mathrm{BD}$ and with MDD. No statistically significant difference was detected in the longitudinal prevalence of PD in patients with $\mathrm{BD}$ or $\mathrm{MDD}$ (online supplementary appendix figure $\mathrm{G}$ ): test for subgroup differences (based on random-effects model): $\mathrm{Q}=0.05, \mathrm{df}=1, \mathrm{P}=0.82$. Heterogeneity was substantial: $I^{2}=88.2 \%(81.3 \%-92.6 \%) ; \quad 0=93.3$, $d f=11, P<0.0001$.

\section{CONCLUSIONS AND CLINICAL IMPLICATIONS}

There is a consensus in the literature of higher rate of psychiatric comorbidity in patients with $\mathrm{BD}$, but with some inconclusiveness about the rates of specific comorbid disorders. Several methodological issues contribute to these inconsistencies. Studies differ in the characteristics of the population under study, by gender, age and composition of samples in terms of BD subtypes or phase of the disorder at the time of assessment. The methods of assessment also influence the chance of correct detection of the cases. Trained lay interviewers are usually employed in epidemiological studies, while clinical studies more often rely on highly experienced researchers. Thus, reliability is often higher in clinical studies, at the expense of the inclusion of more severe cases. Conversely, epidemiological studies, which apply structured interviews, may yield artificially inflated rates because of the multiple allocation of the same symptom. ${ }^{16}$

The current paper analysed 15 studies with data on cross-sectional (point) prevalence of PD in $\mathrm{BD}(\mathrm{n}=3391)$. It also analysed 25 studies with longitudinal data $(n=8226)$. Cross-sectional prevalence of $P D$ ranged in these studies from $2.3 \%$ to $62.5 \%$, while longitudinal prevalence ranged from $2.9 \%$ to $56.5 \%$. The analysis returned a random-effects point prevalence (after exclusion of one potential outlier study) of $13.0 \%(95 \% \mathrm{Cl}$ $7.0 \%$ to $20.3 \%$ ), and a random-effects lifetime estimate (after exclusion of one potential outlier study) of $15.5 \%$ (95\% Cl $11.6 \%$ to $19.9 \%$ ).

Significant heterogeneity was found in both cross-sectional and longitudinal meta-analysis (94.9\% and $95.3 \%$, respectively). In a previous meta-analysis, lifetime comorbidity of PD in patients with $\mathrm{BD}$ was equal to $16.8 \%$ (95\% Cl 13.7 to 20.1$){ }^{18}$ a similar estimate to ours.

There is some evidence that patients with pure mania quite never report panic, which, conversely, is much more prevalent in patients with mixed states or depression (up to $80 \%$, depending on the sample), and often the picture is very complex. ${ }^{19}$ Patients regularly admitted to hospital are likely to display higher rates of psychiatric comorbidity, including PD, than those treated primarily in the community. As a consequence, clinical samples including hospitalised patients with $\mathrm{BD}$ will include a higher proportion of patients with psychiatric comorbidity.

As far as PD is concerned, in the general population the 12-month prevalence of PD was found to vary from $0.8 \%$ to $2.8 \%,{ }^{20-25}$ while the lifetime prevalence was reported to range from $1.4 \%$ to $5.1 \%{ }^{21} 232426-28$ Thus the reported rates for patients with $\mathrm{BD}$ are approximately more than 7-fold higher for cross-sectional prevalence, and more than 4.5-fold higher for longitudinal prevalence, than in the general population. It is worth noticing that the longitudinal rates are approximately double of the 


\section{Study}

Strakowski et al. 1992

Dilsaver et al. 1997

Cosoff and Hafner 1998

Vieta et al. 2001

McElroy et al. 2001

Tamam and Ozpoyraz 2002

Pini et al. 2003

Boylan et al. 2004

Mantere et al. 2006

Otto et al. $2006 \mathrm{a}$

Zutshi et al. 2006a

Coryell et al. 2009

Okan Ibiloglu and Caykoylu 2011

Dell'Osso et al. 2011a

Bellani et al. 2012

\section{Fixed effect model}

\section{Random effects mode}

Heterogeneity: I-squared $=95.9 \%$, tau-squared $=0.1499, p<0.0001$
PD cases Total sample

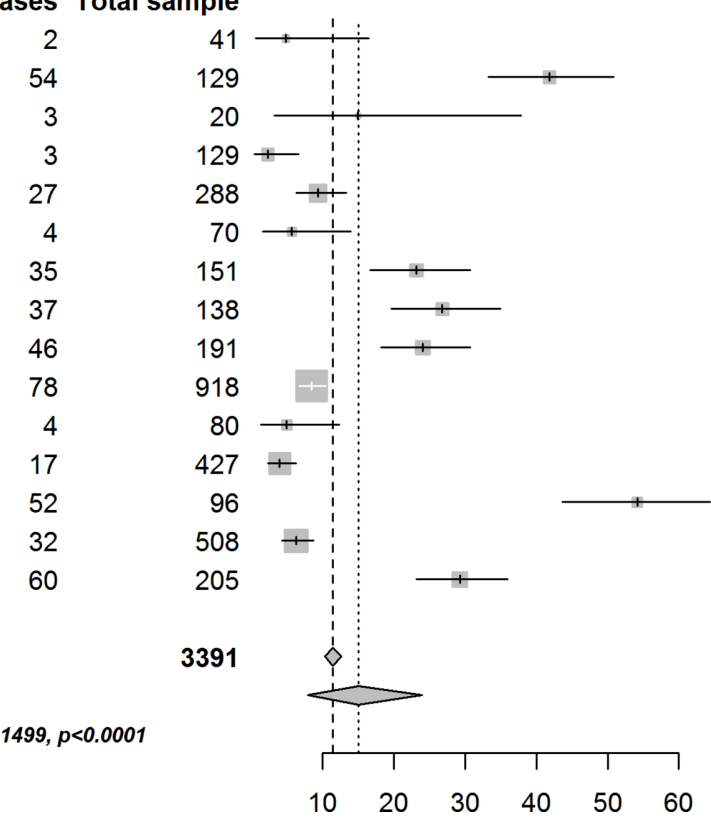

Prop (in \%) $\quad 95 \%-C l$ W(fixed) W(random)

$4.9[0.6 ; 16.5] \quad 1.2 \% \quad 6.1 \%$

$41.9[33.2 ; 50.9] \quad 3.8 \% \quad 6.8 \%$

$15.0 \quad[3.2 ; 37.9] \quad 0.6 \% \quad 5.4 \%$

$2.3 \quad[0.5 ; 6.6] \quad 3.8 \% \quad 6.8 \%$

$9.4[6.3 ; 13.3] \quad 8.5 \% \quad 6.9 \%$

$5.7[1.6 ; 14.0] \quad 2.1 \% \quad 6.5 \%$

$23.2[16.7 ; 30.7] \quad 4.5 \% \quad 6.8 \%$

$26.8[19.6 ; 35.0] \quad 4.1 \% \quad 6.8 \%$

$24.1[18.2 ; 30.8] \quad 5.6 \% \quad 6.9 \%$

$8.5[6.8 ; 10.5] \quad 27.0 \% \quad 7.1 \%$

$5.0[1.4 ; 12.3] \quad 2.4 \% \quad 6.6 \%$

$4.0 \quad[2.3 ; 6.3] \quad 12.6 \% \quad 7.0 \%$

$54.2[43.7 ; 64.4] \quad 2.8 \% \quad 6.6 \%$

$6.3 \quad[4.3 ; 8.8] \quad 15.0 \% \quad 7.0 \%$

$29.3[23.1 ; 36.0] \quad 6.0 \% \quad 6.9 \%$

$11.5[10.4 ; 12.6] \quad 100 \%$

$15.1[7.9 ; 24.0] \quad--\quad 100 \%$

Figure 1 Cross-sectional prevalence of panic disorder (PD) in patients diagnosed with bipolar disorder.

cross-sectional rates in the general population (although some overlap was also reported), while in patients with $\mathrm{BD}$ these rates are very close. It can be advanced that in patients with $\mathrm{BD}, \mathrm{PD}$ is rather exclusively chronic and not episodic, and probably related to temperament, ${ }^{29}$ which does not seem to be the case in the general population.

In the current analysis, both point and longitudinal estimates of PD in $\mathrm{BD}$ were related to significant heterogeneity, which probably reflects heterogeneity in sample composition, differences in methodology and medical settings, as well as geographical differences. No relationship of the prevalence rates with age or gender ratio was found, which is consistent with the incidence and prevalence of PD in the general population.

This widely accepted worst outcome of $\mathrm{BD}$ when comorbid with $\mathrm{PD}$ may depend on PD being often complicated by symptoms of depression, ${ }^{30-32}$ which may trigger a depressive phase in the course of the BD or agitation. ${ }^{33}$
A higher risk of suicide and suicide attempt was reported in patients with $\mathrm{BD}$ comorbid with $\mathrm{PD}$. The frequent association of PD with major depression or substance use and related disorders might explain this finding. As a matter of fact, the evidence in so far is inconclusive. Some studies reported an increased risk of suicide attempts and self-harm in BD comorbid with $\mathrm{PD}$, while other studies failed to find such an association. ${ }^{10}$

Overall, the treatment of $\mathrm{BD}$ is complex, while the treatment of many of its facets remains poorly researched. ${ }^{5-8}$ While in general antidepressants are the treatment of choice for PD, this might not be the case in patients with $\mathrm{BD}$ (at least not in monotherapy) because of the risk of inducing or exacerbating mania. Patients with $\mathrm{BD}$ comorbid with PD are ideal candidates to the use of mood stabilisers, since there is evidence that lithium, lamotrigine and valproic acid/divalproex sodium may alleviate symptoms of anxiety both alone and in combination with antidepressants or second-generation antipsychotics, especially in mixed and

Table 3 Effect sizes in the meta-analysis of studies on panic disorder in patients with bipolar disorder

\begin{tabular}{|c|c|c|c|c|c|c|c|c|}
\hline & $\mathbf{k}$ & $\mathbf{n}$ & Prevalence, n (\%) & $95 \% \mathrm{Cl}(\%)$ & $\mathbf{0}$ & P value & $I^{2}, \mathrm{n}(\%)$ & $95 \% \mathrm{Cl}(\%)$ \\
\hline \multicolumn{9}{|l|}{ Cross-sectional studies } \\
\hline FE model & 15 & 3391 & 11.5 & 10.4 to 12.6 & & & & \\
\hline RE model & 15 & 3391 & 15.1 & 7.9 to 23.9 & 343.5 & $<0.001$ & 95.9 & 94.5 to 97.0 \\
\hline RE model without outliers & 14 & 3295 & 13.0 & 7.0 to 20.3 & 253.9 & $<0.001$ & 94.9 & 92.9 to 96.3 \\
\hline $\mathrm{RE}$ in subgroup analysis 1 & 7 & 1228 & 12.3 & 1.2 to 31.3 & 120.9 & $<0.001$ & 95.0 & 92.0 to 96.9 \\
\hline FE in subgroup analysis 2 & 2 & 161 & 12.9 & 8.0 to 18.7 & & & & \\
\hline
\end{tabular}

Subgroup analysis 1: BD-I samples only.

Subgroup analysis 2: BD-II samples only; since there were two studies only, the FE model was reported.

Longitudinal studies

\begin{tabular}{|c|c|c|c|c|c|c|c|c|}
\hline FE model & 25 & 8226 & 15.5 & 14.7 to 16.3 & & & & \\
\hline RE model & 25 & 8226 & 16.8 & 12.2 to 22.0 & 546.5 & $<0.001$ & 95.6 & 94.5 to 96.5 \\
\hline RE model without outliers & 24 & 8157 & 15.5 & 11.6 to 19.9 & 491.7 & $<0.001$ & 95.3 & 94.0 to 96.3 \\
\hline RE in subgroup analysis 1 & 9 & 2852 & 14.0 & 8.0 to 20.9 & 137.7 & $<0.001$ & 94.2 & 91.0 to 96.3 \\
\hline RE in subgroup analysis 2 & 4 & 217 & 14.8 & 1.7 to 35.8 & 11.1 & 0.011 & 73.1 & 24.2 to 90.4 \\
\hline
\end{tabular}

Subgroup analysis 1: BD-I samples only.

Subgroup analysis 2: BD-II samples only.

BD, bipolar disorder; FE, fixed-effect model; $k$, number of included studies; $n$, number of patients in the included studies; RE, random-effects model with empirical Bayes estimator. 


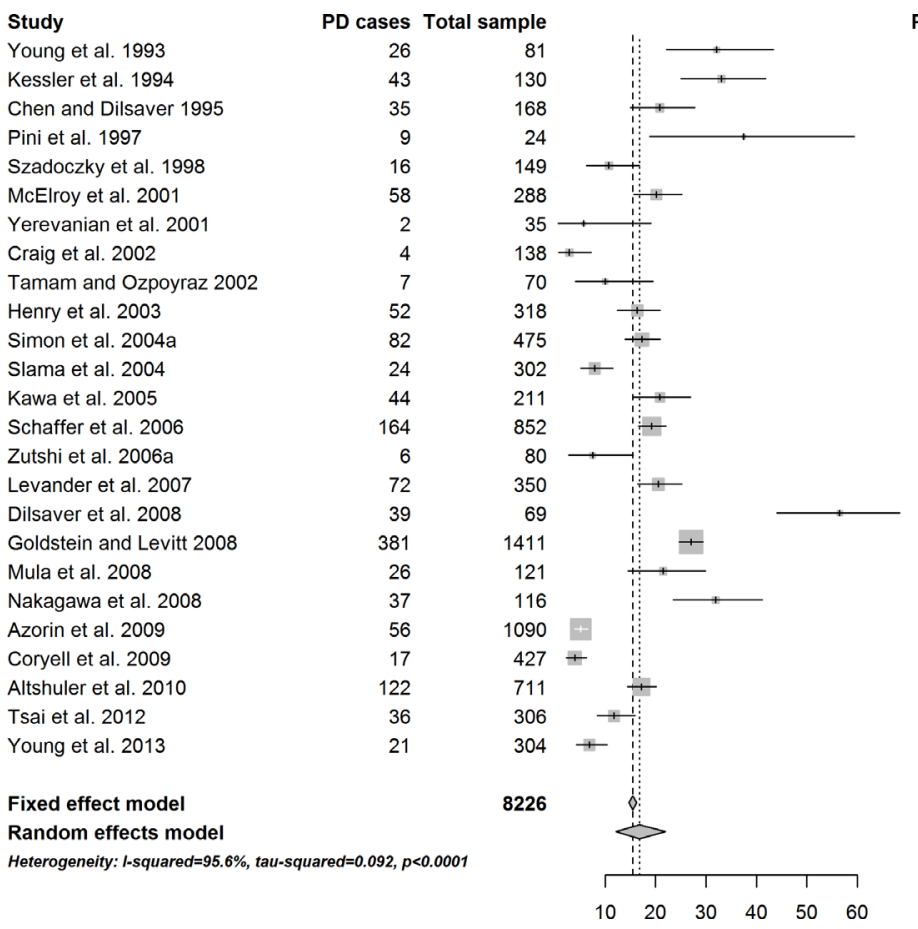

Prop (in \%) $\quad 95 \%$-Cl W(fixed) W(random) $32.1[22.2 ; 43.4] \quad 1.0 \% \quad 3.8 \%$ $33.1[25.1 ; 41.9] \quad 1.6 \% \quad 4.0 \%$ $20.8[15.0 ; 27.8] \quad 2.0 \% \quad 4.1 \%$ $37.5[18.8 ; 59.4] \quad 0.3 \% \quad 3.0 \%$ $10.7 \quad[6.3 ; 16.9] \quad 1.8 \% \quad 4.0 \%$ $20.1[15.7 ; 25.2] \quad 3.5 \% \quad 4.2 \%$ $5.7 \quad[0.7 ; 19.2] \quad 0.4 \% \quad 3.3 \%$ $2.9 \quad[0.8 ; 7.3] \quad 1.7 \% \quad 4.0 \%$ $10.0[4.1 ; 19.5] \quad 0.9 \% \quad 3.7 \%$ $16.4[12.5 ; 20.9] \quad 3.9 \% \quad 4.2 \%$ $17.3[14.0 ; 21.0] \quad 5.8 \% \quad 4.2 \%$ $7.9[5.2 ; 11.6] \quad 3.7 \% \quad 4.2 \%$ $20.9[15.6 ; 27.0] \quad 2.6 \% \quad 4.1 \%$ $19.2[16.7 ; 22.1] \quad 10.3 \% \quad 4.3 \%$ $7.5[2.8 ; 15.6] \quad 1.0 \% \quad 3.8 \%$ $20.6[16.5 ; 25.2] \quad 4.3 \% \quad 4.2 \%$ $56.5[44.0 ; 68.4] \quad 0.8 \% \quad 3.7 \%$ $27.0[24.7 ; 29.4] \quad 17.1 \% \quad 4.3 \%$ $21.5[14.5 ; 29.9] \quad 1.5 \% \quad 4.0 \%$ $31.9[23.6 ; 41.2] \quad 1.4 \% \quad 3.9 \%$ $5.1 \quad[3.9 ; 6.6] \quad 13.2 \% \quad 4.3 \%$ $4.0 \quad[2.3 ; 6.3] \quad 5.2 \% \quad 4.2 \%$ $17.2[14.5 ; 20.1] \quad 8.6 \% \quad 4.3 \%$ $11.8[8.4 ; 15.9]-3.7 \% \quad 4.2 \%$ $6.9[4.3 ; 10.4] \quad 3.7 \% \quad 4.2 \%$

$\begin{array}{rrrr}15.5[14.7 ; 16.3] & 100 \% & - \\ 16.8[12.2 ; 22.0] & -- & 100 \%\end{array}$

Figure 2 Lifetime prevalence of panic disorder (PD) in patients diagnosed with bipolar disorder.

rapid cycling patients. ${ }^{34-39}$ However, the impact of $\mathrm{PD}$ on mood stabilisation and the load of caregiver burden is unclear, ${ }^{40}$ and hard data are not available for the treatment of PD in the frame of $B D$, neither concerning pharmacotherapy nor psychotherapy. ${ }^{41} 42$ The true risk for committing suicide under antiepileptic drugs is still a matter of debate, ${ }^{43-45}$ while psychosocial interventions do not seem to attenuate it. ${ }^{46-49}$

It is worth noticing that most of the papers included in this systematic review were not identified through the scanning of the search engine (PubMed/MEDLINE), but instead they were derived from reference lists of review papers and books. There is no clear explanation for this, but it is possible that the MEDLINE algorithm was unable to locate the information when the search is aimed at data that were not clearly related to the main objective of the study. Overall, accuracy and completeness of review and meta-analytic studies cannot be assured when the data are retrieved from secondary sources, since there always might be an additional secondary source unknown to the authors.

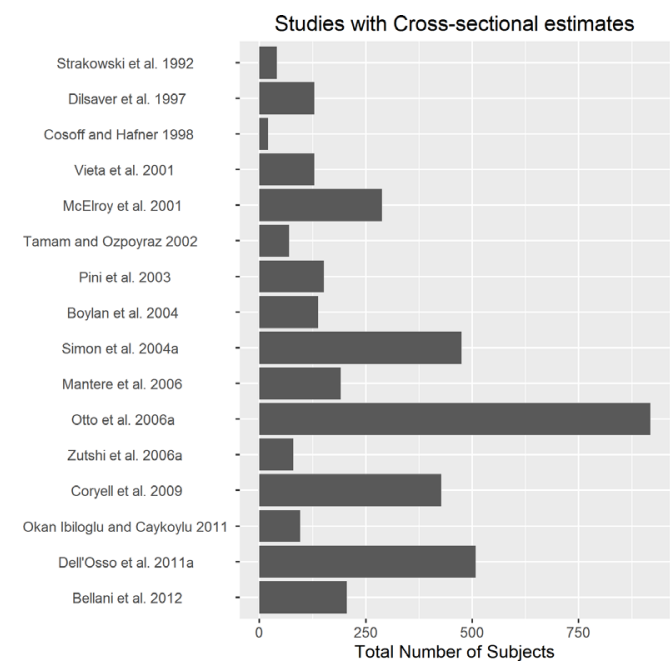

An additional problem hampers the validity of the findings that can be derived from systematic reviews and meta-analysis studies that are based on psychiatric comorbidity in BD. Standard criteria assume that a comorbid anxiety disorder should be diagnosed in $\mathrm{BD}$ only if one can ascertain the independence of the symptoms of the comorbid disorder from those of the main disorder. However, it is probable that most studies reviewed here had used the very simple approach of merely adding up the symptoms. As a matter of fact, no DSM edition made explicit the requirement for independency of symptoms and diagnosis; thus, it cannot be excluded PD symptoms at least partially overlap with some core features of $\mathrm{BD}$ (eg, irritability, excitement).

In conclusion, this meta-analysis proved that there is high rate of comorbidity between $\mathrm{BD}$ and $\mathrm{PD}$, with prevalence rates that are several times higher than in the general population, although with wide variation across studies. PD probably runs a more chronic course in patients with $\mathrm{BD}$ than in the general population. These findings highlight the importance

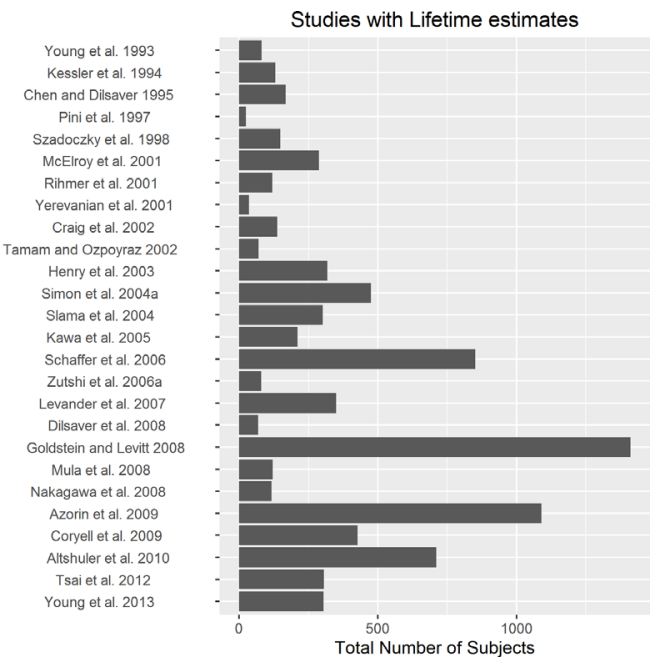

Figure 3 Graphical representation of the sample size of studies reporting cross-sectional and lifetime estimates of panic disorder in patients diagnosed with bipolar disorder. 
of early detection and treatment of PD in BD to prevent chronic outcome, lessen symptom severity, increase chance of remission from a manic or depressive episode, and reduce the risk of suicide and self-harm.

Funding AAV is funded by the Banting Postdoctoral Fellowship Program from the Canadian Institutes of Health Research.

Competing interests None declared.

Patient consent Not required.

Provenance and peer review Not commissioned; externally peer reviewed.

(c) Article author(s) (or their employer(s) unless otherwise stated in the text of the article) 2018. All rights reserved. No commercial use is permitted unless otherwise expressly granted.

- Additional material is published online only. To view please visit the journal online (http://dx.doi.org/10.1136/eb-2017-102858).

doi:10.1136/eb-2017-102858

Received 5 December 2017; Revised 2 March 2018; Accepted 16 March 2018

\section{REFERENCES}

1 Fountoulakis KN, Popovic D, Mosheva M, et al. Mood Symptoms in Stabilized Patients with Schizophrenia: A Bipolar Type with Predominant Psychotic Features? Psychiatr Danub 2017;29:148-54.

2 Goodwin GM, Haddad PM, Ferrier IN, et al. Evidence-based guidelines for treating bipolar disorder: Revised third edition recommendations from the British Association for Psychopharmacology. J Psychopharmacol 2016;30:495-553.

3 Das A. Anxiety disorders in bipolar I mania: prevalence, effect on illness severity, and treatment implications. Indian J Psychol Med 2013;35:53-9.

4 Coryell W, Solomon DA, Fiedorowicz JG, et al. Anxiety and outcome in bipolar disorder. Am J Psychiatry 2009;166:1238-43.

5 Fountoulakis KN, Grunze $\mathrm{H}$, Vieta E, et al. The International College of NeuroPsychopharmacology (CINP) Treatment Guidelines for Bipolar Disorder in Adults (CINP-BD-2017), Part 3: The Clinical Guidelines. Int J Neuropsychopharmacol 2017;20:180-95.

6 Fountoulakis KN, Vieta E, Young A, et al. The International College of Neuropsychopharmacology (CINP) Treatment Guidelines for Bipolar Disorder in Adults (CINP-BD-2017), Part 4: Unmet Needs in the Treatment of Bipolar Disorder and Recommendations for Future Research. Int J Neuropsychopharmacol 2017;20:196-205

7 Fountoulakis KN, Yatham L, Grunze H, et al. The International College of NeuroPsychopharmacology (CINP) Treatment Guidelines for Bipolar Disorder in Adults (CINP-BD-2017), Part 2: Review, Grading of the Evidence, and a Precise Algorithm. Int J Neuropsychopharmacol 2017;20:121-79.

8 Fountoulakis KN, Young A, Yatham L, et al. The International College of Neuropsychopharmacology (CINP) Treatment Guidelines for Bipolar Disorder in Adults (CINP-BD-2017), Part 1: Background and Methods of the Development of Guidelines. Int J Neuropsychopharmacol 2017;20:98-120.

9 Schürhoff F, Bellivier F, Jouvent R, et al. Early and late onset bipolar disorders: two different forms of manic-depressive illness? J Affect Disord 2000;58:215-21.

10 Kilbane EJ, Gokbayrak NS, Galynker I, et al. A review of panic and suicide in bipolar disorder: does comorbidity increase risk? J Affect Disord 2009;115(1-2):1-10.

11 Neves FS, Malloy-Diniz LF, Corrêa H. Suicidal behavior in bipolar disorder: what is the influence of psychiatric comorbidities? J Clin Psychiatry 2009;70:13-18.

12 El-Mallakh RS, Hollifield M. Comorbid anxiety in bipolar disorder alters treatment and prognosis. Psychiatr Q 2008;79:139-50.

13 Fountoulakis K. Clinical Description. In: Fountoulakis K, ed. Bipolar disorder: an evidence-based guide to manic depression: Springer-Verlag Berlin Heidelberg, 2015:27-80.

14 Fountoulakis K. Long-Term Course. In: Fountoulakis K, ed. Bipolar disorder: an evidence-based guide to manic depression: Springer-Verlag Berlin Heidelberg, 2015:81-107.

15 Fountoulakis K. Comorbidity. In: Fountoulakis K, ed. Bipolar disorder: an evidencebased guide to manic depression: Springer-Verlag Berlin Heidelberg, 2015:225-340.

16 Fountoulakis KN. Bipolar disorder: an evidence-based guide to manic depression: Springer, 2015.

17 Goodwin F, Jamison K. Manic-depressive illness. 2nd ed. New York: Oxford University Press, 2007.

18 Nabavi B, Mitchell AJ, Nutt D. A lifetime prevalence of comorbidity between bipolar affective disorder and anxiety disorders: a meta-analysis of 52 interview-based studies of psychiatric population. EBioMedicine 2015;2:1405-19.

19 Ferentinos P, Fountoulakis KN, Lewis CM, et al. Validating a two-dimensional bipolar spectrum model integrating DSM-5's mixed features specifier for major depressive disorder. Compr Psychiatry 2017;77:89-99.
20 Alonso J, Angermeyer MC, Bernert S, et al. Prevalence of mental disorders in Europe: results from the European Study of the Epidemiology of Mental Disorders (ESEMeD) project. Acta Psychiatr Scand Suppl 2004;420:21-7.

21 Grant BF, Hasin DS, Stinson FS, et al. The epidemiology of DSM-IV panic disorder and agoraphobia in the United States: results from the national epidemiologic survey on alcohol and related conditions. J Clin Psychiatry 2006;67:363-74.

22 Andrade LH, Wang YP, Andreoni S, et al. Mental disorders in megacities: findings from the São Paulo megacity mental health survey, Brazil. PLoS One 2012;7:e31879.

23 Roy-Byrne PP, Stang P, Wittchen HU, et al. Lifetime panic-depression comorbidity in the national comorbidity survey. Association with symptoms, impairment, course and help-seeking. Br J Psychiatry 2000;176:229-35.

24 Kessler RC, Chiu WT, Jin R, et al. The epidemiology of panic attacks, panic disorder, and agoraphobia in the national comorbidity survey replication. Arch Gen Psychiatry 2006;63:415-24.

25 Eaton WW, Kessler RC, Wittchen HU, et al. Panic and panic disorder in the United States. Am J Psychiatry 1994;151:413-20.

26 de Jonge P, Roest AM, Lim CC, et al. Cross-national epidemiology of panic disorder and panic attacks in the world mental health surveys. Depress Anxiety 2016;33:1155-77.

27 Weissman MM, Bland RC, Canino GJ, et al. The cross-national epidemiology of panic disorder. Arch Gen Psychiatry 1997;54:305-9.

28 Eaton WW, Anthony JC, Romanoski A, et al. Onset and recovery from panic disorder in the baltimore epidemiologic catchment area follow-up. Br J Psychiatry 1998:173:501-7.

29 Fountoulakis KN, Gonda X, Koufaki I, et al. The role of temperament in the etiopathogenesis of bipolar spectrum illness. Harv Rev Psychiatry 2016;24:36-52.

30 Carvalho AF, Nunes-Neto PR, Castelo MS, et al. Screening for bipolar depression in family medicine practices: prevalence and clinical correlates. J Affect Disord 2014;162:120-7.

31 Bittner A, Goodwin RD, Wittchen HU, et al. What characteristics of primary anxiety disorders predict subsequent major depressive disorder? J Clin Psychiatry 2004;65:618-26.

32 Lamers F, van Oppen P, Comijs HC, et al. Comorbidity patterns of anxiety and depressive disorders in a large cohort study: the Netherlands Study of Depression and Anxiety (NESDA). J Clin Psychiatry 2011;72:341-8.

33 Garriga M, Pacchiarotti I, Kasper S, et al. Assessment and management of agitation in psychiatry: expert consensus. World J Biol Psychiatry 2016;17:86-128.

34 Reinares M, Rosa AR, Franco C, et al. A systematic review on the role of anticonvulsants in the treatment of acute bipolar depression. Int $\mathrm{J}$ Neuropsychopharmacol 2013;16:485-96.

35 Carvalho AF, Mclntyre RS, Dimelis D, et al. Predominant polarity as a course specifier for bipolar disorder: a systematic review. J Affect Disord 2014;163:56-64.

36 Carvalho AF, Dimellis D, Gonda X, et al. Rapid cycling in bipolar disorder: a systematic review. J Clin Psychiatry 2014;75:e578-86.

37 Fountoulakis KN, Kontis D, Gonda X, et al. A systematic review of the evidence on the treatment of rapid cycling bipolar disorder. Bipolar Disord 2013;15:115-37.

38 Fountoulakis KN, Kontis D, Gonda X, et al. Treatment of mixed bipolar states. Int J Neuropsychopharmacol 2012;15:1015-26.

39 Fountoulakis KN, Kasper S, Andreassen 0, et al. Efficacy of pharmacotherapy in bipolar disorder: a report by the WPA section on pharmacopsychiatry. Eur Arch Psychiatry Clin Neurosci 2012;262(Suppl 1):1-48.

40 Pompili M, Harnic D, Gonda X, et al. Impact of living with bipolar patients: Making sense of caregivers' burden. World J Psychiatry 2014;4:1-12.

41 Miziou S, Tsitsipa E, Moysidou S, et al. Psychosocial treatment and interventions for bipolar disorder: a systematic review. Ann Gen Psychiatry 2015;14:19.

42 Pompili M, Innamorati M, Gonda X, et al. Pharmacotherapy in bipolar disorders during hospitalization and at discharge predicts clinical and psychosocial functioning at follow-up. Hum Psychopharmacol 2014;29:578-88.

43 Fountoulakis KN, Gonda X, Baghai TC, et al. Report of the WPA section of pharmacopsychiatry on the relationship of antiepileptic drugs with suicidality in epilepsy. Int J Psychiatry Clin Pract 2015;19:1-10.

44 Fountoulakis KN, Gonda X, Samara M, et al. Antiepileptic drugs and suicidality. J Psychopharmacol 2012;26:1401-7.

45 Siamouli M, Samara M, Fountoulakis KN. Is antiepileptic-induced suicidality a data-based class effect or an exaggeration? A comment on the literature. Harv Rev Psychiatry 2014;22:379-81.

46 Fountoulakis KN, Gonda X, Rihmer Z. Suicide prevention programs through community intervention. J Affect Disord 2011;130(1-2):10-16.

47 Fountoulakis KN, Gonda X, Siamouli M, et al. Psychotherapeutic intervention and suicide risk reduction in bipolar disorder: a review of the evidence. $J$ Affect Disord 2009;113:21-9.

48 Gonda X, Fountoulakis KN, Kaprinis G, et al. Prediction and prevention of suicide in patients with unipolar depression and anxiety. Ann Gen Psychiatry 2007;6:23.

49 Rihmer Z, Gonda X, Fountoulakis KN. Suicide prevention programs through education in the frame of healthcare. Psychiatr Hung 2009;24:382-7. 

bipolar disorder: systematic review and meta-analysis

Antonio Preti, Jelena Vrublevska, Areti Angeliki Veroniki, Tania B

Huedo-Medina, Odysseas Kyriazis and Konstantinos N Fountoulakis

Evid Based Mental Health published online April 10, 2018

Updated information and services can be found at:

http://ebmh.bmj.com/content/early/2018/04/10/eb-2017-102858

\section{These include:}

References This article cites 44 articles, 2 of which you can access for free at: http://ebmh.bmj.com/content/early/2018/04/10/eb-2017-102858\#ref-lis t-1

Email alerting Receive free email alerts when new articles cite this article. Sign up in the service box at the top right corner of the online article.

\section{Notes}

To request permissions go to:

http://group.bmj.com/group/rights-licensing/permissions

To order reprints go to:

http://journals.bmj.com/cgi/reprintform

To subscribe to BMJ go to:

http://group.bmj.com/subscribe/ 